\title{
Meteorological and Climate Modelling Services Tailored to Viticulturists
}

\author{
Ignasi Porras ${ }^{1}$, Josep Maria Solé1, Raül Marcos², Raúl Arasa1 \\ ${ }^{1}$ Meteosim SL, Barcelona, Spain \\ ${ }^{2}$ Barcelona Supercomputing Center (BSC), Barcelona, Spain \\ Email: iporras@meteosim.com
}

How to cite this paper: Porras, I., Solé, J.M., Marcos, R. and Arasa, R. (2021) Meteorological and Climate Modelling Services Tailored to Viticulturists. Atmospheric and Climate Sciences, 11, 148-164. https://doi.org/10.4236/acs.2021.111010

Received: December 15, 2020

Accepted: January 15, 2021

Published: January 18, 2021

Copyright (c) 2021 by author(s) and Scientific Research Publishing Inc. This work is licensed under the Creative Commons Attribution International License (CC BY 4.0).

http://creativecommons.org/licenses/by/4.0/

(c) (i) Open Access

\begin{abstract}
Grape production is likewise inherently interconnected to climate and weather, and, although grapes may grow worldwide, premium wine-grape production occurs in Mediterranean-like climate ranges. Changes in climate and weather patterns are threatening premium wine-grapes, directly affecting the European wine industry. This is because grapevines are extremely sensitive to their surrounding environment, with seasonal variations in yield much higher than other common crops, such as cereals. With a view to making South European wine industry resilient to climate change, VISCA (Vineyards Integrated Smart Climate Application) project has deployed a Climate Service (CS) Decision Support System (DSS) tool that provides to wine producers with well-founded information to be able to apply correctly adaptation strategies on specific grape varieties and locations, and to achieve optimum production results (e.g., yield and quantity). In this paper we show the meteorological, seasonal and climatic models and data sets used to answer the viticulturist needs; from short-term and mid-term forecast to seasonal forecast and climate projections.
\end{abstract}

\section{Keywords}

Weather Extreme Events, Adaptation to Climate Change, Climate Services, Wine Industry, VISCA

\section{Introduction}

Agriculture is a highly dependent sector on heat, sunlight and water, and therefore very sensitive to climate change. According to the current climate projections, weather events worldwide are very likely to become more extreme and frequent. In Europe, Southern countries will be frequently affected by heat 
waves, therefore making this region more vulnerable to droughts and wildfires, which will lead to economic, environmental, and even human losses. In addition, Mediterranean countries are prone to undergo hydrological resources' decrease, due to climate modification (lower precipitation rates) and demographic concentration changes [1] [2]. On the other hand, extreme precipitations will occur especially in the central and northern parts of Europe, giving rise to floods, resulting in a decrease of water quantity and quality due to the fact that hydrological systems will be altered, which may also decrease the water availability in the surrounding regions [3] [4].

Agriculture happens to be the major land use of the earth, and this is expected to increase as population growth and diet changes may drive food needs up to $60 \%$ by 2050 [5] [6]. Therefore, agriculture should ensure food security in a world where 800 million people are currently chronically [7]. Although agriculture has shown ability to adapt to changing conditions, it is very likely that the above projections overpass agriculture's adaptation limits. Even if policies and efforts to reduce emissions prove effective, some climate change is inevitable; therefore, strategies and actions to adapt to climate change impacts are needed [8] [9].

Grape production is not different from the rest of agricultural activity, and they are likewise inherently interconnected to climate and weather, and, although grapes may grow worldwide, premium wine-grape production occurs in Mediterranean-like climate ranges. Changes in climate and weather patterns are threatening premium wine-grapes (e.g., decrease of the grape quality and quantity, undesirable changes in alcohol production, and acid and sugar concentrations), directly affecting the European wine industry [10]. This is because grapevines are extremely sensitive to their surrounding environment, with seasonal variations in yield much higher than other common crops, such as cereals [11].

As wine growers are facing the growing impact of climate change, the demand for enhanced tools designed and able to support them has grown. In particular, there is a high interest for solutions that can provide accurate weather forecast data together with other useful information (e.g., phenological forecast and irrigation optimisation) would be of the greatest value. Until now the proposed strategies aimed at mitigating and adapting to these conditions involved a range of climatic scales and covered multiple aspects of grapevine management (e.g. change of locations and/or grapevine variety selection), but there was no solution integrating all those aspects in a single adapted tool for winegrowers [12] [13] [14].

Responding to these needs, the VISCA (Vineyards Integrated Smart Climate Application, https://www.visca.eu/) an R \& I project co-funded under the Horizon 2020 programme has developed a Climate Service (CS) Decision Support System (DSS) that integrates climate and agricultural modelling, and end-users' specifications, in order to design medium- and long-term adaptation strategies to climate change on vineyards. This objective has been achieved through the integration of climatic data, phenological and irrigation models, and end-users' 
requirements into a system co-designed with relevant South-European wine companies from Spain (Codorniu), Italy (Mastroberardino) and Portugal (Symington), in order to allow them to take well-founded decisions (e.g., harvesting, defoliation, pruning, minimum water needs, etc.); foresee extreme events at short and medium time-scales; ease the decision-making planning months ahead through the use of seasonal predictions and the development of strategies thanks to the climate projections.

In this paper we show the innovative work done within the VISCA DSS, a platform that integrates meteorological and climate modelling services that will improve the work of the end-users in their daily tasks as to support them long term activities. In particular, we show the meteorological models and data sets used to answer the viticulturist needs from short-term to mid-term forecast and from seasonal forecast to climate projections.

\section{Methodology}

\subsection{Demo Site Areas and Cellars}

With a view to making South European wine industry resilient to climate change, VISCA intends to deploy a climate service tool that provides wine producers with well-founded information to be able to correctly apply adaptation strategies on specific grape varieties and locations and, thus, achieve optimum production results (e.g., yield or quality). It has been validated by real demonstration with end-users on three demo sites belonging to wine stakeholders from Spain, Italy and Portugal, which are likewise partners in the consortium: Codorniu, Mastroberardino and Symington. In Table 1 it is shown the end-users demo site characteristics.

\subsubsection{Codorniu (Spain)}

Codorniu wine cellar (https://www.codorniu.com/es) is located in the Denomination of Origin (DO) region called Costers del Segre, in the southwest slope of Raimat hills in Catalonia (Spain). This location confers special and differentiated characteristics: higher sunlight exposure in the afternoon, which allows the grapes to accumulate more degree days, achieving an earlier ripening without losing acidity. These are well drained soils; the slight inclination of the fields confers a natural draining of the rainwater. Being on the slope of the hill causes

Table 1. End-users demo site characteristics.

\begin{tabular}{|c|c|c|c|c|}
\hline & Location & Altitude & $\begin{array}{l}\text { Average annual } \\
\text { precipitation }\end{array}$ & $\begin{array}{c}\text { Average annual } \\
\text { temperature }\end{array}$ \\
\hline Codorniu & $\begin{array}{c}41^{\circ} 39^{\prime} 44.99^{\prime \prime} \mathrm{N}, \\
0^{\circ} 30^{\prime} 26.71^{\prime \prime} \mathrm{E}\end{array}$ & $\sim 300 \mathrm{~mm}$ & $\sim 450 \mathrm{~mm}$ & $\sim 15^{\circ} \mathrm{C}$ \\
\hline Mastroberardino & $\begin{array}{l}41^{\circ} 3{ }^{\prime} 41.40^{\prime \prime} \mathrm{N}, \\
14^{\circ} 58^{\prime} 53.04^{\prime \prime} \mathrm{E}\end{array}$ & $\sim 400 \mathrm{~mm}$ & $\sim 750 \mathrm{~mm}$ & $\sim 16^{\circ} \mathrm{C}$ \\
\hline Symington & $\begin{array}{c}41^{\circ} 14^{\prime} 54.25^{\prime \prime} \mathrm{N} \\
7^{\circ} 6{ }^{\prime} 32.76^{\prime \prime} \mathrm{O}\end{array}$ & $\sim 170 \mathrm{~mm}$ & $\sim 540 \mathrm{~mm}$ & $\sim 16^{\circ} \mathrm{C}$ \\
\hline
\end{tabular}


steady currents of air, which provides a natural cooling down, conferring a special microclimate.

The viticulture performed in this plot is ecological, where the green pruning is especially important: buds and leaves thinning is used to adjust the vine's productive-vegetative equilibrium. The soil composition consists of lutites (mineral clay and limestone) with sandstone (compact fine sand), and it keeps a vegetal cover that contributes to increasing the biodiversity, plus controlling erosion. Regarding general climate characteristics, Costers del Segre region has a continental climate, with annual rainfall between 300 and $450 \mathrm{~mm}$. Annual average temperature is around $15^{\circ} \mathrm{C}$, but variations among the year are remarkable, going below $0^{\circ} \mathrm{C}$ in winter and overpassing $35^{\circ} \mathrm{C}$ in summer. The grape varieties in these plots are Chardonnay and Tempranillo.

\subsubsection{Mastroberardino (Italy)}

Mastroberardino (https://mastroberardino.com/) is an Italian winery located in the Campania region. The demonstration site is located in Mirabella Eclano Estate, in the heart of the Taurasi DO area. The vineyards are surrounded by a large natural landscape, not far from the archaeological excavations of Aeclanum. The estate covers 65 hectares on hill territory with an altitude between 350 and 450 meters above sea level. This estate is spread over several hills with different exposures and it is dedicated to the production of red grapes on the slopes from the Aglianico variety. Actually, this state is epicentre of Aglianico grape production, research and experimentation. The climate in this area is continental and characterized by large thermal day-night excursions (up to $20^{\circ} \mathrm{C}$ ). Average annual rainfall is around $750 \mathrm{~mm}$.

\subsubsection{Symington (Portugal)}

Symington Family Estates (https://www.symington.com/) is one of the principal Port producers and is the leading vineyard owner in the Douro Valley with a total area of 1006 hectares (2486 acres) of vines spread across 27 Quintas dotted around the Douro's three sub-regions (Baixo Corgo, Cima Corgo and Douro Superior) in what is the world's largest mountain vineyard. Portugal's geographic isolation, as well as some past conservatism on the part of its wine producers has worked in the country's favour in terms of the preservation of the rich genetic diversity of its indigenous grape varieties. The demonstration site, Quinta do Ataíde, is located in Douro Superior and it has in total 85 ha vineyards. It consists of two plots with the variety Touriga Nacional, and one plot with Touriga Franca. Although Ataíde has a fairly homogeneous, flat terrain, sandy-loam and loam soil composition, uneven soil drainage has been identified to result in some variance in grape quality. The Douro enjoys its own micro-climate, which is an important reason for the quality and style of its wines. The most important geological features responsible for this are several mountain ranges sheltering it from the Atlantic Ocean influence, giving it a continental climate, with hot and dry summers and cooler and wetter winters. Average annual temperatures range 
from $11.8^{\circ} \mathrm{C}$ to $16.5^{\circ} \mathrm{C}$. Rainfall ranges throughout the year from $50.6 \mathrm{~mm}$ in the wettest month down to $6.9 \mathrm{~mm}$ during the driest month.

\subsection{Modelling Approach}

This section summaries the developments carried out for the meteorological components of the VISCA DSS and shows the meteorological and climate models used for each time-scale, from short-term to mid-term weather forecast and from seasonal forecast to climate projections. Figure 1 shows and schema about the different timescales covered by the meteorological and climate models used in the VISCA DSS and the related skill. Since short-term and mid-term weather forecast have pretty good skills the first forecast days, after some days, the skill decreases rapidly. On the other hand, seasonal forecast and climate projections have a constant fair skill along the forecast lead time. The sub-seasonal to seasonal timescale was not considered within the project.

\subsubsection{Short and Mid-Term Weather Forecast}

During the last years, the use of deterministic Numerical Weather Prediction (NWP) models has increased significantly due to higher accuracy of the models, easier access to community models, computational advances, etc. Despite the inherently uncertainty they can have due to the initial conditions of the atmosphere, several calibrations can be applied to minimize the discrepancies against the real weather conditions. Due to numerical weather prediction models have a wide range of options to set up: physical options, dynamical options, horizontal model resolution, number of vertical layers and density, etc., it is crucial configurate the model with the properly parametrizations and model options [15] [16].

On the other hand, weather forecasts are inherently uncertain because the initial state of the atmosphere can never be known perfectly, and the model equations must be expressed through approximations and simplification in the model system. Furthermore, even the smallest uncertainties in the initial conditions of the forecast model tend to rapidly increase over time because of the chaotic nature of the atmosphere. Therefore, rather than integrating a single forecast from

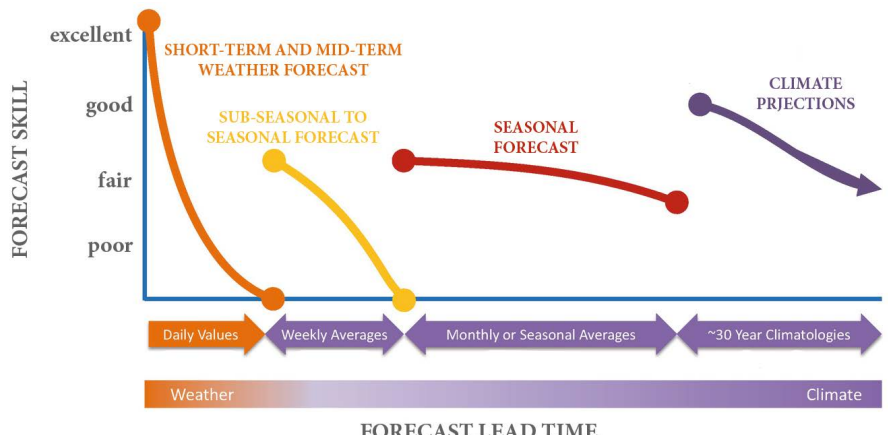

Figure 1. Timescale showing the skill progression from weather and seasonal forecast to climate projections, as used in VISCA DSS. Source: Adapted from iri.columbia.edu/news/ qa-subseasonal-prediction-project. 
a supposedly best guess of the initial state (as was done in short-term forecasting), it has been shown that a better approach would be to start the forecast from several slightly different initial conditions and then derive as many, presumably somewhat different, outcomes from these differing initial conditions (Figure 2). This approach is called ensemble forecasting and as outcome, produces forecasts that are given as probability distribution. From these distributions it is possible to calculate local probabilities for different weather events using thresholds.

In this way and within the VISCA framework, the short-term weather data covers the hourly deterministic forecast for the following 48 hours and provides information of the mean temperature, wind speed, accumulated precipitation, relative humidity and downward short-wave flux. The mid-term, on the other hand, it's a 10-day probabilistic forecast of the same variables.

\section{1) Short-term forecast simulation domains}

To ensure that the model represents as many meteorological phenomena as possible in the different meteorological scales (synoptic, mesoscale, microscale), meteorological modelling has been applied to a nested grid architecture defined by three domains. Since Tables 2-4 show the main characteristics of the simulation domains, Figures 3-5 show the modelling domain schemes for each end-user demo site area.

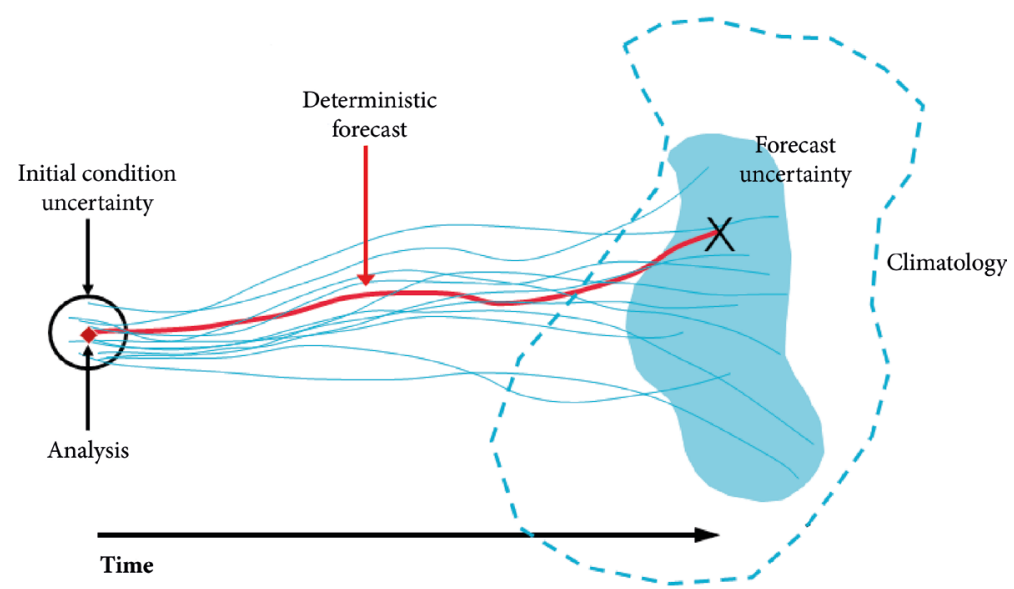

Figure 2. The principle of ensemble-based probabilistic forecasting. In this example it is shown how 12 different ensemble members evolve in time due to slightly different initial conditions.

Table 2. Simulation domains and its characteristics for Codorniu end-user area.

\begin{tabular}{cccc}
\hline \multicolumn{3}{c}{ CODORNIU end-user } \\
\hline Characteristic & Domain D01 & Domain D02 & Domain D03 \\
\hline Description & $\begin{array}{c}\text { South-West Europe and } \\
\text { North West Africa }\end{array}$ & East Spain & $\begin{array}{c}\text { Vineyard } \\
\text { surroundings }\end{array}$ \\
Horizontal resolution & $9 \mathrm{~km} \times 9 \mathrm{~km}$ & $3 \mathrm{~km} \times 3 \mathrm{~km}$ & $1 \mathrm{~km} \times 1 \mathrm{~km}$ \\
Grid size & $370 \times 300$ & $310 \times 310$ & $100 \times 100$ \\
Domain size & $3330 \mathrm{~km} \times 2700 \mathrm{~km}$ & $930 \mathrm{~km} \times 930 \mathrm{~km}$ & $100 \mathrm{~km} \times 100 \mathrm{~km}$ \\
\hline
\end{tabular}



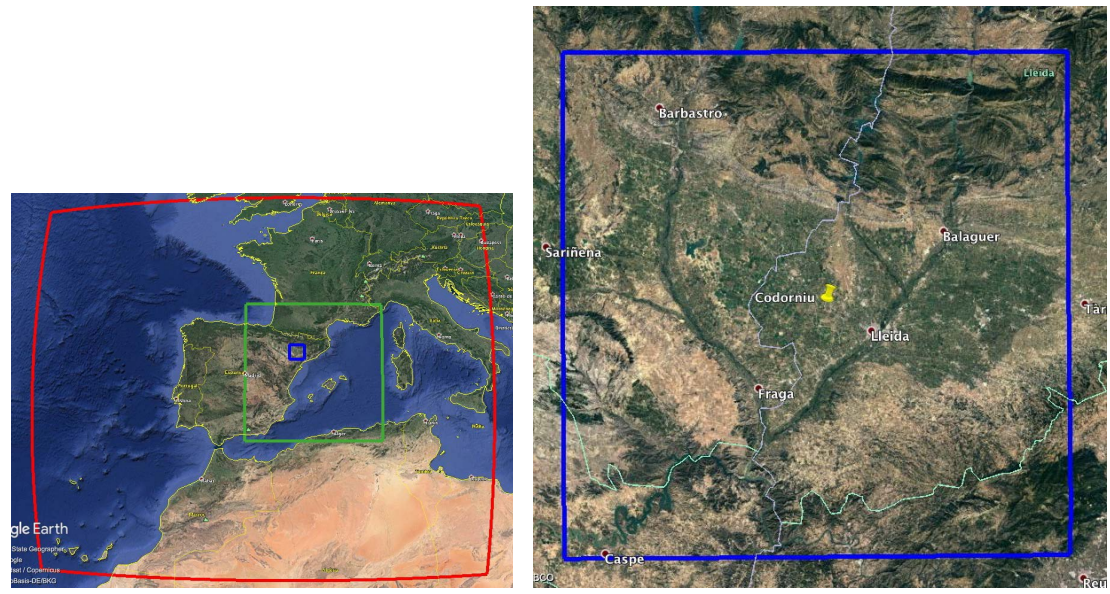

Figure 3. Simulation domains for Codorniu end-user located in Spain. $9 \mathrm{~km}$ grid resolution domain D01 (red), $3 \mathrm{~km}$ grid resolution domain D02 (green) and $1 \mathrm{~km}$ grid resolution domain D03 (blue). Images generated using Google Earth.
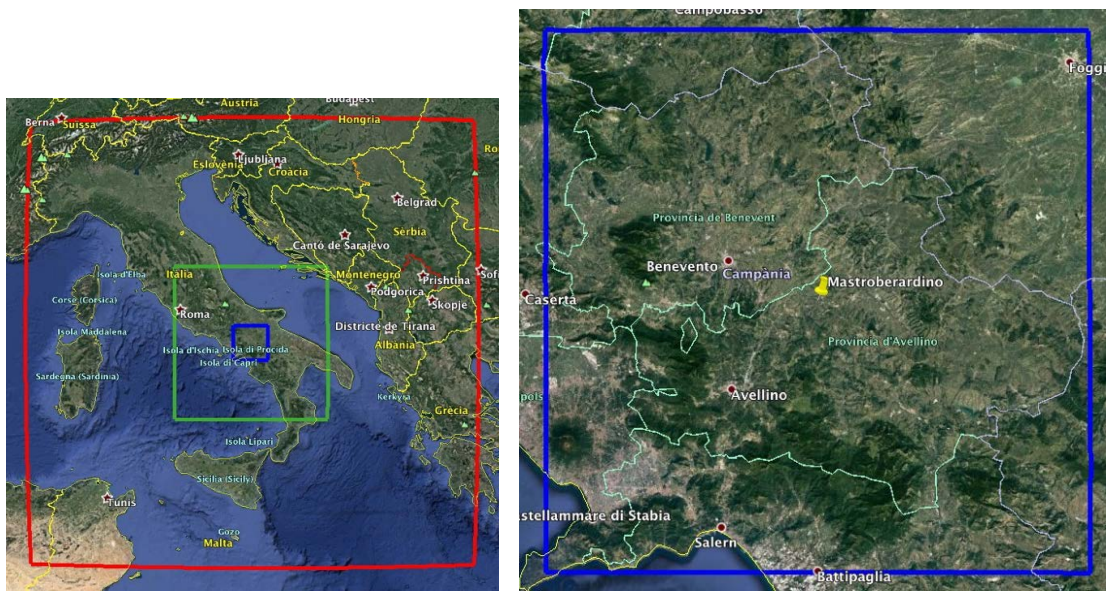

Figure 4. Simulation domains for Mastroberardino end-user located in Italy. $9 \mathrm{~km}$ grid resolution domain D01 (red), $3 \mathrm{~km}$ grid resolution domain D02 (green) and $1 \mathrm{~km}$ grid resolution domain D03 (blue). Images generated using Google Earth.
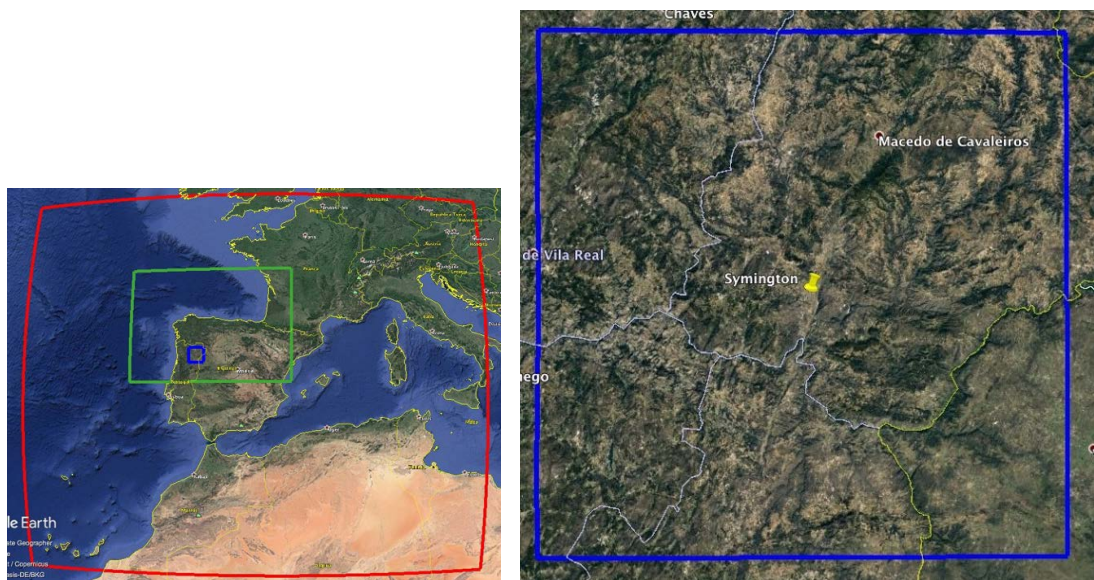

Figure 5. Simulation domains for Symington end-user located in Portugal. $9 \mathrm{~km}$ grid resolution domain D01 (red), $3 \mathrm{~km}$ grid resolution domain D02 (green) and $1 \mathrm{~km}$ grid resolution domain D03 (blue). Images generated using Google Earth. 
Table 3. Simulation domains and its characteristics for Mastroberardino end-user area.

\begin{tabular}{cccc}
\hline \multicolumn{4}{c}{ MASTROBERARDINO end-user } \\
\hline Characteristic & Domain D01 & Domain D02 & Domain D03 \\
\hline Description & $\begin{array}{c}\text { Italy, Nord-West Tunisia, } \\
\text { Balkans region, Corsica and } \\
\text { Southern Europe countries }\end{array}$ & South Italy & $\begin{array}{c}\text { Vineyard } \\
\text { surroundings }\end{array}$ \\
Horizontal resolution & $9 \mathrm{~km} \times 9 \mathrm{~km}$ & $3 \mathrm{~km} \times 3 \mathrm{~km}$ & $1 \mathrm{~km} \times 1 \mathrm{~km}$ \\
Grid size & $151 \times 151$ & $150 \times 150$ & $100 \times 100$ \\
Domain size & $1350 \mathrm{~km} \times 1350 \mathrm{~km}$ & $450 \mathrm{~km} \times 450 \mathrm{~km}$ & $100 \mathrm{~km} \times 100 \mathrm{~km}$ \\
\hline
\end{tabular}

Table 4. Simulation domains and its characteristics for Symington end-user area.

\begin{tabular}{cccc}
\hline \multicolumn{4}{c}{ SYMINGTON end-user } \\
\hline Characteristic & Domain D01 & Domain D02 & Domain D03 \\
\hline Description & $\begin{array}{c}\text { South-West Europe and } \\
\text { North West Africa }\end{array}$ & $\begin{array}{c}\text { West-north Spain and } \\
\text { North Portugal }\end{array}$ & $\begin{array}{c}\text { Vineyard } \\
\text { surroundings }\end{array}$ \\
Horizontal resolution & $9 \mathrm{~km} \times 9 \mathrm{~km}$ & $3 \mathrm{~km} \times 3 \mathrm{~km}$ & $1 \mathrm{~km} \times 1 \mathrm{~km}$ \\
Grid size & $370 \times 300$ & $370 \times 262$ & $100 \times 100$ \\
Domain size & $3330 \mathrm{~km} \times 2700 \mathrm{~km}$ & $1110 \mathrm{~km} \times 786 \mathrm{~km}$ & $100 \mathrm{~km} \times 100 \mathrm{~km}$ \\
\hline
\end{tabular}

\section{2) Short-term forecast data set}

The regional and mesoscale meteorological model used in the project has been the Weather Research and Forecasting-Advanced Research (WRF-ARW) version 3.9.1.1 [17], developed by the National Centre of Atmospheric Research (NCAR). It is a universally used community mesoscale model and a state-of-the-art atmospheric modelling system that is applicable for meteorological research, climate scenarios and numerical weather prediction. WRF-ARW is a fully compressible and non-hydrostatic model with terrain-following hydrostatic pressure coordinate.

Different options that WRF-ARW offers can be combined in many different ways. WRF-ARW has different parameterizations for microphysics, radiation (long and short wave), cumulus, surface layer, planetary boundary layer and land surface as physical options. To obtain WRF-ARW highest accuracy, it is essential to carry out a sensitive analysis of these different options by numerical experiments [17] [18] [19].

In order to reduce the biases of the WRF-ARW model, some improvements have been implemented in order to better perform the precipitation and temperature, two of the main variables that directly affect the vineyards. Firstly, we have chosen the parametrization of physical processes of the model that better perform in the area of interest. Many previous studies have evaluated the sensitivity of WRF-ARW to several parametrization schemes for regional climates over Europe [20]. They showed how the temperature is significantly dependent on the land surface model. On the other hand, they reveal how averaged daily 
precipitation appears to be unaffected by the longwave radiation scheme. They conclude that modelling precipitation is problematic for WRF-ARW with biases of up to $100 \%$. Other studies presented how the precipitation is directly related to land surface model and cumulus scheme parametrizations. Vertical distribution of humidity and temperature were also studied examining the sensitivity of planetary boundary layer schemes [21].

Secondly, we have investigated the potential improvements in using numerical weather prediction model data assimilation system to set-up better initial conditions [22]. Data assimilation is the technique for combining observational data with the model [23]. Within the VISCA framework, the three-dimensional variational data assimilation (3DVar) system has been implemented into the WRF-ARW, and the analysis system used was the Grid point Statistical Interpolation (https://ral.ucar.edu/solutions/products/gridpoint-statistical-interpolation-gsi).

\section{3) Mid-term forecast data set}

The National Centres for Environmental Prediction (NCEP) is the leading centre that produces global forecasts. The Global Ensemble Forecast System (GEFS) forecast ensemble is based upon the notion that erroneous forecasts result from a combination of initial analysis errors and model deficiencies, the former dominating during the first five days. Analysis errors amplify mostly in the sensitive parts of the atmosphere where strong low-pressure areas develop. These errors then move downstream and amplify and thereby affect the large-scale flow. To estimate the effect of possible initial analysis errors and the consequent uncertainty of the forecasts, small changes to the analysis are made creating an ensemble of many different "perturbed" initial states. In order to save computational time, the ensemble members are run at a lower ( 40 kilometres) spatial resolution.

The GEFS consists of 21 separate forecasts or individual ensemble members that are created for lead times of up to 16 days (384 hours) four times a day. However, within the VISCA proposes, GEFS products are considered up to 10 days forecast.

More information about the work done and the results can be found in the VISCA project website (report on weather forecast extreme events, https://www.visca.eu/index.php/the-project-4/deliverables-and-scientific-articles /send/4-delivera-bles-and-scientific-articles/26-visca-deliverable-2-2-report-onweather-forecast-extreme-events).

\subsubsection{Seasonal Forecast}

The production of statistically consistent and reliable predictions is a necessary condition for the elaboration or climate services. To this aim bias correction and downscaling techniques have been applied in the development of the VISCA DSS seasonal forecast. In our case, after comparing the performance of simple bias correction and calibration approaches, we have chosen the latter as the one showing the best results [24]. Regarding the spatial scale gap, the VISCA DSS uses calibration with in-site data as a downscaling adjustment method (after 
comparing it with a perfect prognosis analog approach that gave a poorer outcome).

We have also improved the seasonal forecasts trough the combination of seasonal forecasts from several forecast systems in a multi-model ensemble [25] [26]. The main advantage of the multi-model ensembles comes from a better consistency and reliability than those ensembles from individual systems [27], which are essential properties for the probabilistic seasonal forecast to be usable for decision-making [25] [28]. Nevertheless, the skill enhancement of the multi-model ensemble compared to the best available forecast system is rather marginal and limited to some specific regions.

The estimation of the seasonal forecast quality based on its past performance is a fundamental step to aid end-user decision-making [25], because it allows quantifying the forecast benefit relative to other prediction approaches. Thus, seasonal predictions must be systematically compared to a reference (reanalysis or observations) to assess their overall quality in a multi-faceted process known as forecast quality assessment [29]. Three sources of uncertainty in common scoring metrics of probabilistic predictions should be considered: improper estimates of probabilities from small-sized ensembles, insufficient number of forecast cases, and imperfect reference values due to observation errors. A way to alleviate these problems is to use several scoring measures to offer a comprehensive picture of the forecast quality of the system [30] and to apply statistical inference as often as required. This information is also valuable to decide about the application of the optimal bias correction and downscaling methods [31]. Hence, this quality assessment framework seeks to provide the end-users with the tools to understand which approaches could be better for their interests considering three different probabilistic metrics: fair ranked probability skill score (FRPSS), fair continuous ranked probability skill score (FCRPSS), reliability diagrams; and one deterministic: ensemble-mean correlation.

Within the VISCA framework, the seasonal forecasts provide information for the temperature and precipitation tercile probability for the next six months (monthly forecasts) and the next two seasons (3-month aggregation forecasts). The forecasts have been bias corrected and downscaled following a calibration procedure. Besides, a multi-model approach has been developed (with little gain compared to the use of single forecast). They have been also verified considering four metrics: ensemble correlation, fair ranked probability skill score, fair continuous probability skill score and reliability diagrams. In all the cases, whenever the skill of the forecast is worse than the climatology, the climate information is provided instead of the model forecast.

\section{Seasonal Forecast Data Set}

\section{a) Seasonal Forecast System 4 (SEAS4)}

SEAS4 is the fourth generation of European Centre of Medium-range Weather Forecasts (ECMWF) seasonal prediction system [32]. Is a fully coupled general circulation model that provides operational multi-variable seasonal predictions in a real-time basis. In this study we have focused on period 1981-2015. 
Last 35 years of predictions proceed from the combination of the 30-years hindcasts with the 5-year regular contemporary pool of predictions. All predictions have a minimum of 15-member ensemble (51 members for those which start dates are on 1st day of months February, May, August and November, and at every month since May 2011) and 7-month's forecast horizon. The predictions used for the discussion are those initialized the 1st of November and the 1st of May. We have used monthly mean data for mean temperature, maximum temperature, minimum temperature and precipitation.

\section{b) Seasonal Forecast System 5 (SEAS5)}

SEAS5 is the fifth generation of ECMWF's seasonal forecasting system [33]. It replaces the former SEAS4 and uses the Integrated Forecast System (IFS). The re-forecast of SEAS5 covers a 36-year period, from 1981 to 2017, with an ensemble of 25 members. Compared to the SEAS4 it includes a number of enhancements in the atmospheric resolution, land-surface initialisation and in the ocean model. In the atmospheric component, there are 9 vertical levels. Regarding the land-surface initialisation, the SEAS5 includes a new offline recalculation at the native atmospheric resolution with a revised precipitation forcing. Although this initialisation is still not perfect (the reanalysis and real-time assimilation are not the same), the tests performed show a good degree of consistency between the initialisation of SEAS5 re-forecast and real-time predictions. Finally, the SEAS5 uses the new version of ocean model Nucleus for European Modelling of the Ocean (NEMO), with and upgraded model version, ocean physics and resolution.

c) Météo-France System-6 (MF6)

MF6 is the sixth generation of Météo-France long-range prediction system [34]. The hindcast covers the period 1993-2016 and consists of an ensemble of 25 members. The operational ensemble starts from 2017 and has 51 members. The ensemble spread is generated by a stochastic dynamics' technique in addition to using a lagged initialization. The atmospheric component is the Arpege-IFS [35] which is a complex code designed not only for weather forecast or climate simulation, but also for data assimilation, forecast pre-and post-processing. It has been extended, diversified and complexified since 1986 jointly by Météo-France and ECMWF.

d) Met Office Global Seasonal Forecasting System version 5 (GloSea5)

In VISCA we have used the latest coupled configuration of the GloSea5, in particular the Global Coupled 2.0 (GloSea5-GC2) [36]. The re-forecast of GloSea5-GC2 covers a 36-year period, from 1981 to 2016, with an ensemble of 28 members. Overall, the GloSea5-GC2 is shown to be an improvement on the configurations used currently, particularly in terms of modes of variability (e.g. mid-latitude and tropical cyclone intensities, the Madden-Julian Oscillation and El Niño Southern Oscillation).

More information about the work done and the results can be found in the VISCA project website (seasonal forecasts quality assessment report, https://www.visca.eu/index.php/the-project-4/deliverables-and-scientific-articles 
/send/4-deliverables-and-scientific-articles/25-visca-deliverable-2-1-seasonal-for ecasts-quality-assessment-report).

\subsubsection{Climate Projections}

The purpose of this section is to show an overview of the work done within the project. The idea was to analyse the change of climate variables which are impacting the most in the viticulture, namely mean precipitation and temperature, but also temperature and precipitation extreme events for the coming decades until 2100.

Within the VISCA framework, first of all, a set of climate indices were defined giving key information about the impact on the wine sector: seasonal temperature climatology, defined as the mean temperature over a period of a 3-monthly season; seasonal daily precipitation climatology, defined as the mean of maximum daily precipitation over a period of a 3-monthly season; and finally, the Winkler index that classifies a location according to the range of the Growing Degree-Days (GDD, https://mrcc.illinois.edu/gismaps/info/gddinfo.htm). The analysis was performed at European scale, but also specific results were provided for the 3 demo sites provided by the end-users of the project.

Climate Projection Data Set

\section{a) Gridded observational dataset (E-OBS)}

E-OBS data has been used as observational dataset. This is a gridded observational dataset derived through interpolation of the European Climate Assessment and Data (ECA \& D, https://www.ecad.eu/) station data described collected at European scale. The station dataset comprises a network of 2316 stations, with the highest station density in Ireland, the Netherlands and Switzerland, and lowest density in Spain, Northern Africa, the Balkans and Northern Scandinavia. The number of stations used for the interpolation differs through time and by variable.

The E-OBS dataset is derived through a three-stage process:

- Monthly means of temperature and precipitation are first interpolated to a 0.1-degree latitude by longitude grid using three-dimensional (latitude, longitude, elevation) thin plate splines.

- Daily anomalies, defined as the departure from the monthly mean temperature or precipitation, are interpolated to the same 0.1-degree grid, and combined with the monthly mean grid. For temperature, daily anomalies are interpolated using kriging with elevation as an external variable. For precipitation kriging is first used o interpolate the state (wet/dry); after that the magnitude at 'wet' 0.1-degree grid points is interpolated using universal kriging.

- Finally, the 0.1-degree points are used to compute area-average values at the four E-OBS grid resolutions (0.25-degree and 0.5-degree regular latitude-longitude grid and 0.22-degree and 0.44-degree Lat-Lon rotated-pole grids).

In the present study the 0.22-degree Lat-Lon rotated-pole grid has been used, because it coincides with the grid of EURO-CORDEX grid (see chapter below). 
The full dataset covers the period from 1950 to 2017 (both included).

\section{b) EURO-CORDEX climate projections}

EURO-CORDEX (https://www.euro-cordex.net/) is the European branch of the international CORDEX initiative, which is a program sponsored by the World Climate Research Program (WRCP) to organize an internationally coordinated framework to produce improved regional climate change projections for all land regions world-wide. The CORDEX-results are being used worldwide to assess for climate change impact and to feed adaptation studies within the timeline of the Fifth Assessment Report (AR5) of the Intergovernmental Panel on Climate Change (IPCC) and beyond.

EURO-CORDEX consists of a set of simulations provided by the participating groups. Nowadays, mainly dynamical downscaling simulations are available, namely the output of a regional climate model (RCM) coupled to a Global Climate Model (GCM) or a Reanalysis. The outputs of these simulations are available on rotated-pole regular grids at 0.11 degrees of horizontal resolution $(\sim 12$ $\mathrm{km}$, depending on the latitude). They are free to download from Earth System Grid Federation (ESGF) nodes like https://esgf-data.dkrz.de/projects/esgf-dkrz/.

More information about the work done and the results can be found in the VISCA project website (decadal projection performance report, https://www.visca.eu/index.php/the-project-4/deliverables-and-scientific-articles /send/4-deliverables-and-scientific-articles/83-2-5).

\section{Conclusions}

The extension and the quality of wine production are strongly related to the environmental conditions of the grape growing season. Grapevine growing factors are determined within a narrow climatic range in which the adequate heat accumulation, the availability of enough water and the low risk of extreme temperature episodes are required. As an example, in 2017 a historically low production ( $8 \%$ less in comparison with 2016) was registered due to climate conditions.

While climate patterns can differ radically from one year to another (climate variability), climate change is more concerning, because a significant shift in the long-term climatology would make the wine business unsustainable. Adaptation measures are most probably needed to adapt the current grape varieties to warmer climate conditions and the presence of more frequent and more intense extreme events such as heat waves, heavy rainy or long dry spells.

Future suitability of a certain viticulture region highly depends on the change on the mean patterns on temperature and precipitation in the coming decades, but also on the impact of extreme temperature and precipitation. For that reason, estimation regional changes in temperature and precipitation and the derived impacts on the suitability of vine cultivation are of paramount importance for the business of gives critical information for making strategic decisions and investments in the near future, which will make the industry more resilient and adapted to climate change. 
The VISCA DSS is a tool that integrates meteorological and climate information, among others, in order to provide well-funded information to the end-users to design medium- and long-term adaptation strategies to climate change on vineyards; foresee extreme events at short and medium time-scales; ease the decision-making planning months ahead through the use of seasonal predictions and the development of strategies thanks to the climate projections. In this paper we have shown the meteorological, seasonal and climatic models, and the data sets used to answer the viticulturist needs for all time-scales.

As a short-term weather model, we have used the WRF-ARW version 3.9.1.1, providing hourly forecast information for the following 48 hours for those interesting variables for viticulturists: mean temperature, wind speed, accumulated precipitation, relative humidity and downward short-wave flux.

GEFS information has been used to compute probabilistic forecast up to 10 -days in advance for the same variables.

SEAS4, SEAS5, MF6 and GloSea5 seasonal prediction systems have been used to compute the seasonal forecast. This provides information for the temperature and precipitation tercile probability for the next six months (monthly forecasts) and the next two seasons (3-month aggregation forecasts).

Within the climate projections, we have used E-OBS data to perform climatic indices related to the wine sector and EURO-CORDEX climate projections to analyse the projected change over the period 2010-2099.

More information about the work done and the results can be found in the VISCA project website: Report on weather forecast extreme events, https://www.visca.eu/index.php/the-project-4/deliverables-and-scientific-articles /send/4-delivera-bles-and-scientific-articles/26-visca-deliverable-2-2-report-onweather-forecast-extreme-events; Seasonal forecasts quality assessment report, https://www.visca.eu/index.php/the-project-4/deliverables-and-scientific-articles /send/4-deliverables-and-scientific-articles/25-visca-deliverable-2-1-seasonal-for ecasts-quality-assessment-report; Decadal projection performance report, https://www.visca.eu/index.php/the-project-4/deliverables-and-scientific-articles /send/4-deliverables-and-scientific-articles/83-2-5.

\section{Acknowledgements}

This work has been developed within the framework of the project VISCA (Vineyards' Integrated Smart Climate Application), an R\&I project co-funded under the Horizon 2020 programme with a total budget of $3.20 \mathrm{M} €$. The authors gratefully acknowledge VISCA consortium, composed of 11 members from different fields including end-users (Codorniu, Mastroberardino and Symington), for their support and collaboration.

\section{Conflicts of Interest}

The authors declare no conflicts of interest regarding the publication of this paper. 


\section{References}

[1] Intergovernmental Panel on Climate Change (2019) Climate Change and Land: An IPCC Special Report on Climate Change, Desertification, Land Degradation, Sustainable Land Management, Food Security, and Greenhouse Gas Fluxes in Terrestrial Ecosystems.

https://www.ipcc.ch/site/assets/uploads/2019/11/SRCCL-Full-Report-Compiled-191 128.pdf

[2] United States Environmental Protection Agency (n.d.) Climate Change Indicators: Weather and Climate. https://www.epa.gov/climate-indicators/weather-climate

[3] Working at Bio Intelligence Service (2012) Literature Review on the Potential Climate Change Effects on Drinking Water Resources across the EU and the Identification of Priorities among Different Types of Drinking Water Supplies. Contract Number 070326/SER/2011/610284/D1.

https://ec.europa.eu/environment/archives/water/adaptation/pdf/ADWICE_FinalR eport.pdf

[4] Singh, S. and Tiwari, S. (2019) Climate Change, Water and Wastewater Treatment: Interrelationship and Consequences. In: Singh, R., Kolok, A. and Bartelt-Hunt. S., Eds., Water Conservation, Recycling and Reuse: Issues and Challenges, Springer, Singapore, 203-214. https://doi.org/10.1007/978-981-13-3179-4_11

[5] Food and Agriculture Organization (2009) Global Agriculture towards 2050. http://www.fao.org/fileadmin/templates/wsfs/docs/Issues_papers/HLEF2050_Globa 1_Agriculture.pdf

[6] Science Communication Unit, University of the West of England, Bristol (2013) Science for Environment Policy In-Depth Report: Sustainable Food.

https://ec.europa.eu/environment/integration/research/newsalert/pdf/sustainable_f ood_IR8_en.pdf

[7] Food and Agriculture Organization, International Fund for Agricultural Development, United Nations Children's Fund, World Food Programme and World Health Organization (2020) The State of Food Security and Nutrition in the World 2020. Transforming Food Systems for Affordable Healthy Diets. Food and Agriculture Organization, Rome.

[8] Metzger, M.J. and Rounsevell, M.D.A. (2011) A Need for Planned Adaptation to Climate Change in the Wine Industry. Environmental Research Letters, 6, Article ID: 031001. https://doi.org/10.1088/1748-9326/6/3/031001

[9] Hannah, L., Roehrdanz, P., Ikegami, M., Shepard, A., Shaw, M., Tabor, G., Zhi, L., Marquet, P. and Hijmans, R. (2013) Climate Change, Wine, and Conservation. Proceedings of the National Academy of Sciences of the United States of America, 110, 6907-6912. https://doi.org/10.1073/pnas.1210127110

[10] Keller, M. (2010) Managing Grapevines to Optimise Fruit Development in a Challenging Environment: A Climate Change Primer for Viticulturists. Australian Journal of Grape and Wine Research, 16, 56-69. https://doi.org/10.1111/j.1755-0238.2009.00077.x

[11] Chloupek, O., Hrstkova, P. and Schweigert, P. (2004) Yield and Its Stability, Crop Diversity, Adaptability and Response to Climate Change, Weather and Fertilisation over 75 Years in the Czech Republic in Comparison to Some European Countries. Field Crops Research, 85, 167-190. https://doi.org/10.1016/S0378-4290(03)00162-X

[12] Mosedale, J., Abernethy, K., Smart, R., Wilson, R. and Maclean, I. (2016) Climate Change Impacts and Adaptive Strategies: Lessons from the Grapevine. Global Change Biology, 22, 3814-3828. https://doi.org/10.1111/gcb.13406 
[13] Viguie, V., Lecocq, F. and Touzard, J.M. (2014) Viticulture and Adaptation to Climate Change. Journal International des Sciences de la Vigne et du Vin, hal-00982086, 55-60. https://hal-enpc.archives-ouvertes.fr/hal-00982086/document

[14] Adapting Viticulture to Climate Change (2016) Adapting Viticulture to Climate Change: Guidance Manual to Support Winegrowers' Decision-Making. https://www.adviclim.eu/wp-content/uploads/2015/06/B1-deliverable.pdf

[15] Reboredo, B., Arasa, R. and Codina, B. (2015) Evaluating Sensitivity to Different Options and Parameterizations of a Coupled Air Quality Modelling System over Bogotá, Colombia. Part I: WRF Model Configuration. Open Journal of Air Pollution, 4, 47-64. http://dx.doi.org/10.4236/ojap.2015.42006

[16] Arasa, R., Porras, I., Domingo-Dalmau, A., Picanyol, M., Codina, B., González, M. (2016) Defining a Standard Methodology to Obtain Optimum WRF Configuration for Operational Forecast: Application over the Port of Huelva (Southern Spain). Atmospheric and Climate Sciences, 6, 329-350. http://dx.doi.org/10.4236/acs.2016.62028

[17] Skamarock, W.C., Klemp, J.B., Dudhia, J., Gill, D.O., Barker, D.M., Duda, M.G., Huang, X.-Y., Wang, W. and Powers, J.G. (2008) A Description of the Advanced Research WRF Version 3. No. NCAR/TN-475+STR, University Corporation for Atmospheric Research, Boulder. http://dx.doi.org/10.5065/D68S4MVH

[18] Arasa, R., Soler, M.R. and Olid, M. (2012) Evaluating the Performance of a Regional-Scale Photochemical Modelling System: Part I. Ozone Predictions. International Scholarly Research Notices, 2012, Article ID: 860234. https://doi.org/10.5402/2012/860234

[19] Saha, S., Moorthi, S., Wu, X., Wang, J., Nadiga, S., Tripp, P., Behringer, D., Hou, Y.-T., Chuang, H.-Y., Iredell, M., Ek, M., Meng, J., Yang, R., Peña, M., Van den Dool, H., Zhang, Q., Wang, W., Chen, M. and Becker, E. (2014) The NCEP Climate Forecast System Version 2. Journal of Climate, 27, 2185-2208.

https://doi.org/10.1175/JCLI-D-12-00823.1

[20] Mooney, P.A., Mulligan, F.J. and Fealy, R. (2013) Evaluation of the Sensitivity of the Weather Research and Forecasting Model to Parameterization Schemes for Regional Climates of Europe over the Period 1990-95. Journal of Climate, 26, 1002-1017. https://doi.org/10.1175/JCLI-D-11-00676.1

[21] Stergiou, I., Tagaris, E. and Sotiropoulou, R. (2017) Sensitivity Assessment of WRF Parameterizations over Europe. Proceedings of the 2nd International Electronic Conference on Atmospheric Sciences, 16-31 July 2017, 119.

https://doi.org/10.3390/ecas2017-04138

[22] Yang, J.H., Dua, K.Q., Wu, J.K., Qin, X., Shi, P.H., Liu, H.C., et al. (2014) Effect of Data Assimilation Using WRF-3DVAR for Heavy Rain Prediction on the Northeastern Edge of the Tibetan Plateau. Advances in Meteorology, 2015, Article ID 294589. https://doi.org/10.1155/2015/294589

[23] Kleist, D., Parrish, D.F., Derber, J.C., Treadon, R., Wu, W. and Lord, S. (2009) Introduction of the GSI into the NCEP Global Data Assimilation system. Weather and Forecasting, 24, 1691-1705. https://doi.org/10.1175/2009WAF2222201.1

[24] Torralba, V., Doblas-Reyes, F.J. and Gonzalez-Reviriego, N. (2017) Uncertainty in Recent Near-Surface Wind Speed Trends: A Global Reanalysis Intercomparison. Environmental Research Letters, 12, Article ID: 114019.

https://doi.org/10.1088/1748-9326/aa8a58

[25] Doblas-Reyes, F.J., Pavan, V. and Stephenson, D. (2003) The Skill of Multi-Model Seasonal Forecasts of the Wintertime North Atlantic Oscillation. Climate Dynamics, 
21, 501-514. https://doi.org/10.1007/s00382-003-0350-4

[26] Weigel, A.P., Liniger, M. and Appenzeller, C. (2008) Can Multi-Model Combination Really Enhance the Prediction Skill of Probabilistic Ensemble Forecasts? Quarterly Journal of the Royal Meteorological Society, 134, 241-260.

https://doi.org/10.1002/qj.210

[27] Hagedorn, R., Doblas-Reyes, F.J. and Palmer, T.N. (2005) The Rationale behind the Success of Multi-Model Ensembles in Seasonal Forecasting-I. Basic Concept. Tellus $A$, 57, 219-233. https://doi.org/10.3402/tellusa.v57i3.14657

[28] Alessandrini, S., Sperati, S. and Pinson, P. (2013) A Comparison between the ECMWF and COSMO Ensemble Prediction Systems Applied to Short-Term Wind Power Forecasting on Real Data. Applied Energy, 107, 271-280.

https://doi.org/10.1016/j.apenergy.2013.02.041

[29] Mason, S.J. and Baddour, O. (2008) Statistical Modelling, in Seasonal Climate: Forecasting and Managing Risk. Springer, Dordrecht, 167-206.

[30] Jolliffe, I. and Stephenson, D. (2012) Forecast Verification: A Practitioner's Guide in Atmospheric Science. Wiley and Sons, $240 \mathrm{p}$.

[31] Ruffault, J., Martin-StPaul, N.K. and Duffet, C. (2014) Projecting Future Drought in Mediterranean Forests: Bias Correction of Climate Models Matters! Theoretical and Applied Climatology, 117, 113-122. https://doi.org/10.1007/s00704-013-0992-z

[32] Molteni, F., Stockdale, T., Balmaseda, M., Balsamo, G., Buizza, R., Ferranti, L., Magnusson, L., Mogensen, K., Palmer, T. and Vitart, F. (2011) The New ECMWF Seasonal Forecast System (System 4). No. 656, European Centre for Medium-Range Weather Forecasts, Reading. http://dx.doi.org/10.21957/4nery093i

[33] European Centre for Medium-Range Weather Forecasts (2017) SEAS5 User Guide. https://www.ecmwf.int/sites/default/files/medialibrary/2017-10/System5_guide.pdf

[34] Documentation of the METEO-FRANCE Pre-Operational Seasonal Forecasting System (2017).

https://www.umr-cnrm.fr/IMG/pdf/system6-technical.pdf

[35] Déqué, M., Dreveton, C. and Braun, A. (1994) The ARPEGE/IFS Atmosphere Model: A Contribution to the French Community Climate Modelling. Climate Dynamics, 10, 249-266. https://doi.org/10.1007/BF00208992

[36] Met Office Seasonal Prediction System: GloSea5. https://www.metoffice.gov.uk/research/climate/seasonal-to-decadal/gpc-outlooks/u ser-guide/technical-glosea5 